\title{
Characteristics of Streptococcus mutans Isolated from Human Dental Plaque and Blood
}

\author{
R. R. FACKLAM \\ Center for Disease Control, Public Health Service, Department \\ of Health, Education, and Welfare, Atlanta, Georgia 30333
}

\begin{abstract}
A comparison of physiological characteristics of Streptococcus mutans isolates from human blood (54 strains) and dental plaque (50 strains) showed that there were no appreciable differences among the strains. The species can be defined and differentiated by a combination of serological and physiological properties. The strains were tested for 30 physiological characteristics. Lancefield extracts of each strain were tested for precipitin reactions with antisera for Lancefield groups A, B, C, D, E, F, G, H, K, O, and A variant. The failure of Lancefield extracts of $S$. mutans to react with streptococcal group D antisera, the formation of characteristic gelatinous deposits in 5\% sucrose broth, and acid formation in mannitol broth are the three major criteria for recognizing $S$. mutans.
\end{abstract}

Several recent studies $(10,11,17,22)$ have shown that streptococci isolated from dental plaque resemble Streptococcus mutans. Clarke in $1924(12)$ described this organism isolated from dental plaque, and Abercombie and Scott in 1928 (1) reported this organism in a single case of infective endocarditis. Even though the organism could be differentiated from the other streptococci, textbooks and taxonomy manuals have not published descriptions of the organism. The seventh edition of Bergey's Manual of Determinative Bacteriology (7) does not have a description of $S$. mutans. This report describes a physiological identification scheme and a comparison of physiological characteristics of $S$. mutans isolated from human dental plaque and blood.

\section{MATERIALS AND METHODS}

Stock strains of $S$. mutans were obtained from the various investigators listed in Table 1 . The human plaque isolates were kindly supplied by $\mathrm{L}$. A. Thomson, National Institute of Dental Research, Bethesda, Md. The human blood isolates were submitted to the Center for Disease Control (CDC) by various state and city health departments or by private investigators with whom we have collaborative studies. The procedures for serological grouping, determining hemolytic and catalase activities, and testing for the majority of physiological reactions listed in Table 2 have been previously described $(18,19)$. Tests that have not been previously described are tolerance to 2 and $4 \% \mathrm{NaCl}$ broths and determination of hydrolysis of hippurate. The 2 and $4 \%$ broths of $\mathrm{NaCl}$ were prepared by adding $\mathrm{NaCl}$ to heart infusion broth (Difco) up to the desired concentration. Dextrose
$(0.1 \%)$ and an indicator (bromocresol purple) were added to the media. The medium for determining hippurate hydrolysis was prepared by adding sodium hippurate (1\% final concentration) to heart infusion broth. The three media were tubed in 16 by $125 \mathrm{~mm}$ screw-capped tubes and sterilized by autoclaving. Tolerance to 2 and $4 \% \mathrm{NaCl}$ broth was determined by rotating the tubes in front of an incandescent lamp and observing for growth after 24,48 , and $72 \mathrm{~h}$. Hydrolysis of hippurate was determined by pipetting $0.8 \mathrm{ml}$ of supernatant from a 48 -h growth of hippurate broth to a Kahn tube; $0.2 \mathrm{ml}$ of ferric chloride solution (12 $\mathrm{g}$ of $\mathrm{FeCl}_{3} \cdot 6 \mathrm{H}_{2} \mathrm{O}$ in $100 \mathrm{ml}$ of acqueous $\mathrm{HCl}$ ) was added to the supernatant. A heavy precipitate that remained longer than 15 min indicated that hippurate had been split. An immediate clearing or no precipitate indicated that hippurate was not split.

Extracellular polysaccharide production (presumably glucan) was determined by the following methods:

(i) Five percent sucrose agar. Glucan production typical of $S$. sanguis and $S$. mutans resulted in highly refractile, adherent or white-dry, adherent growth on the agar. Levan production, typical of $S$. salivarius, resulted in opaque, gummy, nonadherent growth. Typical $S$. bovis growth was similar to the growth of $S$. salivarius but somewhat less gummy and rarely adherent to the medium. Large or small colonies that were mucoidal and nonadherent were considered as being negative or having no extracellular polysaccharide production.

(ii) Five percent sucrose broth. Glucan production was indicated when the broth was partially or completely gelled, typical of $S$. sanguis. Glucan production was also indicated when gelatinous, adherent deposits formed on the bottom and walls of the growth tube, typical of $S$. mutans. An increase in viscosity of the broth indicated the production of slime (unknown polysaccharide) typical of $S$. bovis. Negative reactions occurred when no gelling, deposits, or increase in viscosity occurred. 


\section{RESULTS}

Table 1 shows the biotypes of the stock strains tested. A typical $S$. mutans will grow in $2 \% \mathrm{NaCl}$ broth, form acid in litmus milk, and form acid in the following $1 \%$ carbohydrate broths: trehalose, mannitol, sucrose, inulin, lactose, sorbitol, esculin, and raffinose. Typical strains will not grow in $0.1 \%$ methylene blue milk or at $10 \mathrm{C}$. Typical strains do not hydrolyze starch, hippurate, or gelatin nor do they form acid in $1 \%$ broths of glycerol or arabinose. The majority of strains, but not all, do not grow in broth containing $6.5 \% \mathrm{NaCl}$. Nearly all the typical strains form extracellular polysaccharides (glucans) in either 5\% sucrose agar or $5 \%$ sucrose broth or in both.

The exceptional physiological reactions which make up the biotypes described are listed in Table 1. The majority of these exceptions involve only three reactions: failure to split esculin and failure to form acid in sorbitol and in raffinose broths.

Table 2 shows the percentage of strains exhibiting the different hemolytic reactions in
$5 \%$ rabbit blood agar. The source of the specimen seemed to affect the kind of hemolysis observed. More blood isolates were nonhemolytic $(74 \%)$ than were plaque isolates $(38 \%)$, and more of the plaque isolates gave alpha reactions $(54 \%)$ than did blood isolates (7\%). The percentage of stock strains and the total percentages of all isolates that produce the three kinds of hemolysis were similar to those reported by Edwardsson (17).

The results of reacting Lancefield extracts of the $S$. mutans strains with CDC streptococcal grouping antisera are shown in Table 2. The majority of strains $(89 \%)$ failed to react with any of the antisera. These antisera are standard Lancefield grouping antisera produced with Lancefield group A (S. pyogenes), group B ( $S$. agalactiae), etc. Three strock strains, one blood isolate, and nine plaque isolates reacted with serogroup E antisera. One blood and one plaque isolate reacted weakly with serogroup $F$ antisera. Also, one blood isolate and one strain isolated from an endocervix (other) reacted with serogroup $\mathrm{K}$ antisera. All these precipitin reactions (including E) were very weak and

TABLE 1. Identification and biotype of S. mutans stock strains

\begin{tabular}{|c|c|c|}
\hline Biotype & Strain identification & Exceptional reactions \\
\hline I & $\begin{array}{l}\text { Carlsson's OPK-1, KPSK-2, KPK-3, } \\
\text { and MPK-1; Jordan, Englander, and } \\
\text { Keyes' PP-3,4, 5, 6, 7, 8, 9, 10, } \\
12 \text {, and } 3720 ; \text { Gibbons' LM-7 and } \\
\text { GS-5. Zinner's BHT. Fitzgerald } \\
\text { and Keyes' E49; NTCC } 10449 \text { and } \\
\text { strain 214T.P. }\end{array}$ & None \\
\hline II & No stock strains & Fails to split esculin \\
\hline III & $\begin{array}{l}\text { Jordan, Englander, and Keyes' PP-1 } \\
\text { and PP-11; Fitzgerald and Jordan's } \\
\text { HS-6, FA-1, and K1-R }\end{array}$ & $\begin{array}{l}\text { Fails to form acid in } 1 \% \\
\text { raffinose broth }\end{array}$ \\
\hline IV & $\begin{array}{l}\text { Jordan's SL-1; Fitzgerald's 6715-8; } \\
\text { and Zinners' AHT }\end{array}$ & $\begin{array}{l}\text { Fails to split esculin or } \\
\text { form acid in raffinose } \\
\text { broths }\end{array}$ \\
\hline $\mathrm{V}$ & Fitzgerald and Keyes' E49-2 & $\begin{array}{l}\text { Fails to form acid in } 1 \% \\
\text { sorbitol broth }\end{array}$ \\
\hline VI & Carlsson's MEI & $\begin{array}{l}\text { Fails to form acid in } \\
\text { sorbitol and raffinose } \\
\text { broth }\end{array}$ \\
\hline VII & Carlsson's OIHI & $\begin{array}{l}\text { Fails to split esculin or } \\
\text { form acid in sorbitol and } \\
\text { raffinose broths }\end{array}$ \\
\hline VIII & DeStoppelaar's C67-25 (mutant) & $\begin{array}{l}\text { Fails to form acid in } 1 \% \\
\text { lactose broth }\end{array}$ \\
\hline
\end{tabular}


probably represent cross-reacting antibodies in the CDC grouping antisera. No attempt was made to validate these reactions as being homologous to beta-hemolytic group E, F, or K streptococci.

Table 2 also shows the results of the tests used to detect extracellular polysaccharide production by $S$. mutans (presumably glucan). All but two blood isolates and two isolates from other sources formed glucan on 5\% sucrose agar. One stock strain failed to produce glucan in $5 \%$ sucrose broth. This was DeStoppelaar's (16) nondextran-forming mutant. The two blood isolates and five of the ten plaque isolates that failed to produce glucan in 5\% sucrose broth also failed to grow after 3 days of aerobic incubation. Two strains from other sources (dog bite wound and jaw exudate) failed to produce glucan in $5 \%$ sucrose broth. These two strains were the only two $S$. mutans strains that failed to produce glucan in both $5 \%$ sucrose broth and agar.

Table 3 gives the results of $142 \mathrm{~S}$. mutans strains in 29 physiological tests. The source of the specimen was found to have little or no influence on the physiological test results. All or the majority of strains were able to grow in $2 \% \mathrm{NaCl}$ broth, form acid and clot litmus milk, and form acid in trehalose, mannitol, sucrose, inulin, lactose, sorbitol, salicin, esculin, raffinose, and melibiose broths. All or nearly all of the strains failed to grow in $0.1 \%$ methylene blue milk or at $10 \mathrm{C}$. None of the strains hydrolyzed hippurate or gelatin or tolerated $0.04 \%$ tellurite. The majority of the strains did not grow in $6.5 \% \mathrm{NaCl}$ broth and failed to hydrolyze starch. None of the strains formed acid in glycerol, arabinose, and melezitose broths. Variable reactions were observed in bile-esculin medium, growth in $4 \% \mathrm{NaCl}$ broth, growth at $45 \mathrm{C}$, growth on 10 and $40 \%$ bile, and reduction of $0.1 \%$ tetrazolium.

Table 4 shows the number of strains of $S$. mutans isolated from various sources that gave the biotype reactions listed in Table 1. More than $95 \%$ of the strains did not have any exceptional reactions. Only four of 54 blood isolates and 11 of 50 plaque isolates deviated from the biotype I reactions. One of six isolates from other sources deviated from biotype I reactions. In general, the biochemical patterns observed were consistent with those observed by other investigators $(11,17,22)$.

\section{DISCUSSION}

At the CDC, biotyping of $S$. mutans is not considered to be necessary or valid. It is
TABLE 2. Percentage of S. mutans strains giving different hemolytic and serological reactions and forming dextrans on sucrose media

\begin{tabular}{l|r|r|r|r|r}
\hline Reaction & $\begin{array}{c}\text { Stock } \\
\text { strains } \\
(32)^{a}\end{array}$ & $\begin{array}{c}\text { Blood } \\
(54)\end{array}$ & $\begin{array}{c}\text { Plaque } \\
(50)\end{array}$ & $\begin{array}{c}\text { Other } \\
(6)\end{array}$ & $\begin{array}{c}\text { Total } \\
(142)\end{array}$ \\
\hline Hemolysis & & & & & \\
$\quad$ Alpha & 31 & 7 & 54 & 33 & 30.3 \\
Beta & 3 & 19 & 8 & 17 & 11.3 \\
None & 66 & 74 & 38 & 50 & 58.4 \\
& & & & & \\
Serogroups & 9 & 2 & 18 & 0 & 8.4 \\
E & 0 & 2 & 2 & 0 & 1.4 \\
F & 0 & 2 & 0 & 17 & 1.4 \\
K & 91 & 94 & 80 & 63 & 88.8 \\
None $b$ & & & & & \\
Dextran on: & & & 100 & 67 & 97.2 \\
5\% Sucrose & 100 & 93 & 100 & 67 & 91.2 \\
$\quad$ agar & & & & & \\
5\% Sucrose & 97 & 96 & 80 & & \\
$\quad$ broth & & & & & \\
\hline
\end{tabular}

${ }^{a}$ Number of strains.

$b$ Streptococcal grouping antisera used were specific antisera for groups A, B, C, D, E, F, G, H, K, and O streptococci.

$c^{c}$ All strains that failed to form dextrans were biotype I except one plaque biotype IV strain. The one stock strain that failed to produce dextran in $5 \%$ sucrose broth was DeStoppelaar's non-dextran-producing mutant. The two blood isolates and five of the 10 plaque isolates that failed to produce dextrans in $5 \%$ sucrose broth failed to grow in the medium. Two strains from other sources (dog bite wound and jaw exudate) failed to produce dextran on either the agar or broth. No other strains failed to produce dextran in both tests.

presented here as a convenient method for demonstrating atypical strains. In the description of the species, we accept the variable reactions such as splitting of esculin and acid formation in raffinose and sorbitol broths. Strains that fail to give positive reactions in one or more of these three tests, but give all the other expected reactions of $S$. mutans, are considered to be $S$. mutans strains even though they are atypical. All streptococci giving alpha and gamma reactions in blood agar are speciated by "spectrum analysis" (18). Spectrum analysis is observing the results of the reactions listed in Tables 2 and 3 by unknown strains; the resulting reactions fit known reactions of stock strains of streptococcal species.

The hemolytic activity and serogrouping (primarily for elimination of group D reaction) of the strains help to identify $S$. mutans. It is important that these characteristics be used in conjunction with the different physiological characteristics, because identification of $S$. 
TABLE 3. Percentage of $S$. mutans strains giving different physiological reactions ${ }^{a}$

\begin{tabular}{|c|c|c|c|c|c|}
\hline Test & Stock strains & Blood & Plaque & Other & Total \\
\hline Bile esculin & 53 & 17 & 48 & 17 & 35.9 \\
\hline Methylene blue milk & 0 & 2 & 4 & 0 & 0.7 \\
\hline $6.5 \% \mathrm{NaCl}$ broth & 16 & 2 & 12 & 0 & 8.5 \\
\hline $4.0 \% \mathrm{NaCl}$ broth & 50 & 30 & 46 & 50 & 40.8 \\
\hline $2.0 \% \mathrm{NaCl}$ broth & 97 & 93 & 92 & 100 & 93.6 \\
\hline Growth at $10 \mathrm{C}$ & 0 & 0 & 0 & 0 & 0 \\
\hline Growth at $45 \mathrm{C}$ & 90 & 30 & 64 & 83 & 57.5 \\
\hline Growth on $10 \%$ bile & 34 & 48 & 86 & 67 & 59.2 \\
\hline Growth on $40 \%$ bile & 22 & 19 & 62 & 33 & 35.2 \\
\hline Hydrolysis of starch & 0 & 11 & 0 & 17 & 4.9 \\
\hline Hydrolysis of hippurate & 0 & 0 & 0 & 0 & 0 \\
\hline Hydrolysis of gelatin & 0 & 0 & 0 & 0 & 0 \\
\hline Tolerance to $0.04 \%$ tellurite & 0 & 0 & 0 & 0 & 0 \\
\hline Reduces $0.1 \%$ tetrazolium & 37 & 22 & 56 & 0 & 36.6 \\
\hline Litmus milk acid & 100 & 100 & 100 & 100 & 100.0 \\
\hline Litmus milk clot & 93 & 81 & 96 & 67 & 88.7 \\
\hline \multicolumn{6}{|l|}{ Acid from $1 \%$ broths: } \\
\hline Trehalose & 100 & 100 & 100 & 100 & 100.0 \\
\hline Mannitol & 100 & 100 & 100 & 100 & 100.0 \\
\hline Sucrose & 100 & 100 & 100 & 100 & 100.0 \\
\hline Inulin & 100 & 100 & 100 & 100 & 100.0 \\
\hline Lactose & 97 & 98 & 100 & 100 & 98.6 \\
\hline Sorbitol & 91 & 98 & 92 & 100 & 94.4 \\
\hline Salicin $b$ & 93 & 100 & 78 & 100 & 92.1 \\
\hline Esculin & 88 & 96 & 84 & 83 & 88.7 \\
\hline Raffinose & 78 & 98 & 84 & 100 & 88.7 \\
\hline Melibiose $^{b}$ & 83 & 88 & 43 & 100 & 80.9 \\
\hline Glycerol & 0 & 0 & 0 & 0 & 0 \\
\hline Arabinose & 0 & 0 & 0 & 0 & 0 \\
\hline Melezitose ${ }^{b}$ & 0 & 0 & 0 & 0 & 0 \\
\hline
\end{tabular}

${ }^{a}$ Same number of strains as in Table 2 .

$b$ Not all strains were tested.

TABLE 4. Number of biotypes identified from various sources

\begin{tabular}{l|r|r|r|r|r}
\hline \multirow{2}{*}{ Biotype } & \multicolumn{3}{|c|}{ Source } & \multirow{2}{*}{} & \multirow{2}{*}{} \\
\cline { 2 - 4 } & Blood & Plaque & Other & Total & Percentage \\
\hline I & 50 & 39 & 5 & 94 & 85.4 \\
II & 1 & 3 & 1 & 5 & 4.5 \\
III & 0 & 2 & 0 & 2 & 1.8 \\
IV & 1 & 2 & 0 & 3 & 2.7 \\
V & 1 & 0 & 0 & 1 & 0.9 \\
VI & 0 & 1 & 0 & 1 & 0.9 \\
VII & 0 & 3 & 0 & 3 & 2.7 \\
VIII & 1 & 0 & 0 & 1 & 0.9 \\
Total & 54 & 50 & 6 & 110 & \\
\hline
\end{tabular}

mutans on hemolytic and/or serological properites is not possible.

The capacity of streptococci to form glucans helps to differentiate the streptococci. $S$. sanguis strains form glucans in both $5 \%$ sucrose agar and broth. Glucan formation by $S$. sanguis cannot be reliably differentiated from glucan formation by $S$. mutans on 5\% sucrose agar. However, most $S$. sanguis strains gel $5 \%$ sucrose broth, but $S$. mutans strains do not. $S$. mutans forms sticky gelatinous deposits on the media container (20). Also $S$. sanguis does not form acid in mannitol broth, which helps to differentiate it from $S$. mutans. In our collection of clinical isolates of streptococci giving alphareactions in blood agar, 150 strains are identified as $S$. sanguis. All 150 strains form acid in inulin broth and do not form acid in mannitol broth; nearly all $(90 \%)$ of the strains form glucan on either one or both $5 \%$ sucrose agar and 5\% sucrose broth. Forty-nine $(33 \%)$ of these strains formed acid in raffinose, seven (4\%) formed acid in sorbitol; and eight $(5 \%)$ formed acid in both sorbitol and raffinose broths. Three raffinose-positive strains and three raffinose-negative strains produced the gelatinous deposits in 5\% sucrose broth (typical of $S$. mutans). None of the sorbitol-positive strains did so.

Six strains of streptococci identified as mannitol-negative $S$. mutans (Bratthalls' type d) 
were obtained. Of these strains, only one fermented raffinose and two fermented sorbitol. The raffinose-positive strain formed acid in inulin, sucrose, and lactose broth, split esculin, and produced gelatinous deposits in 5\% sucrose broth. Two other "mannitol-negative mutans" strains formed acid in trehalose, lactose, sucrose, and inulin broth and produced gelatinous deposits in 5\% sucrose broth. Two strains formed acid in trehalose, sorbitol, lactose, sucrose, and inulin, failed to split esculin or form acid in raffinose broth, and gave negative reactions in 5\% sucrose broth. The other "mannitol-negative mutans strain" formed acid in trehalose, lactose, sucrose, and inulin, failed to split esculin or form acid in raffinose broth, and did not form glucans in either 5\% sucrose broth or sucrose agar. The mannitol-negative strains could not be differentiated from typical $S$. sanguis strains except that they formed the gelatinous deposits in the $5 \%$ sucrose broth. This one reaction was not considered sufficient to differentiate streptococcal species. The reaction in $5 \%$ sucrose broth should be considered as a variable reaction for identification of streptococci. Therefore, these strains were considered $S$. sanguis regardless of serological reaction with $S$. mutans typing antisera (I. L. Shklair and H. J. Keene, Abstr. Annu. Meet. Amer. Soc. Microbiol. 1973, G57, p. 35).

Glucan formation and failure to split hippurate by $S$. mutans serves to differentiate $S$. mutans from $S$. uberis. S. uberis forms acid in the same carbohydrate broths as does $S$. mutans. Also, extracts of some strains of $S$. $u$ beris react with streptococcal group $\mathrm{E}$ antisera (15). Although $S$. mutans has antigenic (probable group $E$ antigen) relationships and certain physiological (mannitol and sorbitol fermentation) similarities to $S$. uberis and $S$. infrequens (serogroup E beta-hemolytic streptococci), it is easily differentiated from these streptococci by differences in serological, hemolytic, and physiological characteristics. Each of these are distinct, clearly definable species.

Some strains of $S$. mutans share physiological characteristics of the group D streptococci. The tolerance to $40 \%$ bile, the bile-esculin reaction, and $6.5 \% \mathrm{NaCl}$ tolerance are characteristics of $S$. faecalis and its varieties, $S$. faecium and $S$. durans. The majority of these strains grow at 10 $\mathrm{C}$, tolerate $0.1 \%$ methylene blue milk, and yield serological group D reactions (16). These characteristics along with other physiological differences easily differentiate (by spectrum analysis) these organisms from $S$. mutans. The group D species, $S$. bovis, shares a number of physiological characteristics with $S$. mutans. $S$. bovis is differentiated from $S$. mutans by obtaining serological group D reactions from extracts of $S$. bovis strains. Extracellular polysaccharide formation by $S$. bovis in $5 \%$ sucrose broth is different from that of $S$. mutans. $S$. bovis increases the viscosity of the broth but does not gel or form the gelatinous deposits in the broth. Glucan formation by $S$. bovis on $5 \%$ sucrose agar is usually, but not always, different from that of $S$. mutans. $S$. bovis occasionally produces adherent, highly refractile colonies on $5 \%$ sucrose agar (typical of $S$. mutans) but more often produces the nonadherent, opaque gumdrop colonies. Typical strains of $S$. bovis always hydrolyze starch, whereas $S$. mutans strains do not. An occasional $S$. mutans strain will hydrolyze starch very weakly, unlike $S$. bovis which hydrolyzes starch very strongly. The colonial morphology on blood agar also helps in recognizing $S$. mutans. It grows poorly; a thin film of growth is barely visible after $24 \mathrm{~h}$ at 35 C. $S$. bovis grows very readily, like the enterococci; lush growth is observed at $24 \mathrm{~h}$ at 35 C. When examined by spectrum analysis, these organisms can be differentiated.

It is not surprising to find that $S$. mutans is antigenically heterogenous. Bratthall's studies $(3,4,5,6)$ have shown five different serotypes of $S$. mutans, one of which is homologous to serogroup E streptococci. In view of our own studies, some strains of $S$. mutans may be antigenically related to streptococci other than group $\mathrm{E}$ streptococci (group $\mathrm{K}$ and $\mathrm{F}$ ). The deoxyribonucleic acid (DNA) homology studies of Coykendall $(13,14)$ also support the fact that the taxon $S$. mutans includes a heterologous collection of strains. Both Bratthall and Coykendall feel that their data support each other. Coykendall reported that there was more DNA homology between strains of the same Bratthall serotype and less homology between strains of different Bratthall serotypes; however, he has reported on only nine strains and has not included type " $\mathrm{e}$ " in his studies.

Recently, Brown and Patterson (8) demonstrated a heterogeneity among $S$. mutans strains by electrophoretic mobility of mannitol-1-phosphate dehydrogenases from a variety of $S$. mutans strains. Bleiweis et al. (2) reported that the cell wall composition (polysaccharide, teichoic acid, and peptidoglycan) among certain strains of $S$. mutans was not homologous. All these data by different investigators point out the heterogeneity of this collection of streptococci termed $S$. mutans.

Chemical definition of the type antigens of $S$. mutans has been attempted primarily by two groups of investigators. Mukasa and Slade (23, 
24) believe that the antigens of $S$. mutans types "a" and " $b$ " are polysaccharide in nature, but Bleiweis and co-investigators $(2,25)$ believe that the antigenic determinants for types " $a$ " and "b" $S$. mutans are teichoic acids. Recently, Burgess and Edwards (9) demonstrated that different extraction procedures yielded different chemical compositions of the type " $b$ " antigen. Their results tended to support the results of Bleiweis and his co-workers rather than the results of Mukasa and Slade. These results may indicate that there is more than one specific antigen for each type, but these discrepancies should be resolved before accepting serological methods for classification and differentiation of $S$. mutans. The problem of clearly defining serotypes "c", "d," and "e" has not been completely resolved. The chemical nature of the antigens has not been elucidated, and troublesome cross-reactions between types "c" and "e" and between types "a" and " $d$ " remain to be solved $(6,21)$.

Investigators should be aware that these type antigens of $S$. mutans may not be species-specific, i.e., other streptococci may possess these antigens. Bratthall (3) warned that the "type specific" antisera for $S$. mutans had been tested for specificity only with a battery of organisms considered most likely to possess common antigens to $S$. mutans. The true specificity of the antisera will be demonstrated when the sera are used for epidemiological studies involving "wild" strains of streptococci that have been shown to be $S$. mutans by physiological reactions. Grenier et al. (21) reported a significant discrepancy between serological (fluorescent antibody) identification and cultural isolation of $S$. mutans. S. mutans was culturally isolated in $60 \%$ of the samples that gave positive fluorescent-antibody reactions for $S$. mutans. There are several possible explanations offered for this discrepancy, and nonspecific reactions is one of the possible reasons.

This taxon is as well defined (physiologically) as many of the species of streptococci and is better defined than any of the viridans streptococci. I do not think there is any value at the present in dividing $S$. mutans into additional species. Recognizing the different antigenic compositions of strains should be sufficient for epidemiological studies. Investigators should use caution in the use of terminology when referring to the typing of $S$. mutans. It is unfortunate that the term "group" has been used by some investigators when referring to the different type antigens of $S$. mutans. Since the letter system (A, B, C) has been widely adopted to refer to the Lancefield system of identification, it will become confusing to have another system of naming antigens with the term "group" and letters used for identifying antigens among the streptococci. Typing species of streptococci is clear and convenient when arabic or roman numerals are used to designate subtypes.

The antibiotic susceptibilities of $S$. mutans isolated from documented cases of subacute bacterial endocarditis are quite uniform (C. Thornsberry, C. N. Baker, and R. R. Facklam, Prog. Abstr. Intersci. Conf. Antimicrob. Ag. Chemother., 13th, Washington, D.C., Abstr. $209,1973)$. The organism is highly susceptible to penicillin and patients are cured of S. mutans subacute bacterial endocarditis quite successfully with penicillin therapy (unpublished data). Thus, there is no medical reason to subdivide the species. It is felt that $S$. mutans is a clearly definable species and can be recognized by its physiological characteristics. The failure of Lancefield extracts of $S$. mutans to react with streptococcal group D antisera, the formation of characteristic gelatinous deposits in 5\% sucrose broth, and acid formation in mannitol broth are major criteria for recognizing $S$. mutans.

\section{LITERATURE CITED}

1. Abercombie, G. F., and W. M. Scott. 1928. A case of infective endocarditis due to Streptococcus mutans. Lancet 2:697-699.

2. Bleiweis, A. S., R. A. Crag, S. E. Coleman, and I. Van De Rijn. 1971. The streptococcal cell wall: structure, antigenic composition, and reactivity with lysozyme. J. Dent. Res. (Suppl.) 50:1118-1130.

3. Bratthall, D. 1969. Immunodiffusion studies on the serological specificity of streptococci resembling Streptococcus mutans. Odeontol. Revy 20:231-243.

4. Bratthall, D. 1970. Demonstration of five serological groups of streptococcal strains resembling Streptococcus mutans. Odontol. Revy 21:143-152.

5. Bratthall, D. 1972. Serological studies on Streptococcus mutans. Odontol. Revy (Suppl.) 23:1-20.

6. Bratthall, D. 1972. Immunofluorescent identification of Streptococcus mutans. Odontol. Revy 23:181-196.

7. Breed, R. S., E. G. D. Murray, and N. R. Smith. 1957. Bergey's manual of determinative bacteriology, p. 508-529, 7th ed. The Williams \& Wilkins Co., Baltimore.

8. Brown, A. T., and C. E. Patterson. 1972. Heterogeneity of Streptococcus mutans strains based on their mannitol-1-phosphate dehydrogenases: criterion for rapid classification. Infect. Immunity 6:422-424. 
9. Burgess, T. E., and J. R. Edwards. 1973. Chemical characterization of a cell wall antigen from Streptococcus mutans FAI. Infect. Immunity 8:491-493.

10. Carlsson, J. 1967. Presence of various types of non-hemolytic streptococci in dental plaque and in other sites of the oral cavity in man. Odontol. Revy 18:55-74.

11. Carlsson, J. 1968. A numerical taxonomic study of human oral streptococci. Odontol. Revy 19:137-160.

12. Clarke, J. K. 1924. On the bacterial factor in the aetiology of dental caries. Brit. J. Exp. Pathol. 5:141-147.

13. Coykendall, A. L. 1971. Genetic heterogeneity in Streptococcus mutans. J. Bacteriol. 106:192-196.

14. Coykendall, A. L., O. P. Daily, M. J. Kramer, and M. E. Beath. 1971. DNA-DNA hybridization studies of Streptococcus mutans. J. Dent. Res. 50:1131-1140.

15. Cullen, G. 1967. Classification of Streptococcus uberis with biochemical tests. Res. Vet. Sci. 8:83-88.

16. DeStoppelaar, J. D. 1971. Decreased cariogenicity of a mutant of Streptococcus mutans. Arch. Oral. Biol. 16:971-975.

17. Edwardsson, S. 1968. Characteristics of caries-inducing human streptococci resembling Streptococcus mutans. Arch. Oral. Biol. 13:637-646.

18. Facklam, R. R. 1972. Recognition of group D streptococcal species of human origin by bio- chemical and physiological tests. Appl. Microbiol. 23:1131-1139.

19. Facklam, R. R., and M. D. Moody. 1970. Presumptive identification of group D streptococci: the bile-esculin test. Appl. Microbiol. 20:245-250.

20. Gibbons, R. J., and M. Nygaard. 1968. Synthesis of insoluble dextran and its significance in the formation of gelatinous deposits by plaque-forming streptococci. Arch. Oral. Biol. 13:1249-1262.

21. Grenier, E. M., W. C. Eveland, and W. J. Loesche. 1973. Identification of Streptococcus mutans serotypes in dental plaque by fluorescent antibody techniques. Arch. Oral. Biol. 18:707-715.

22. Guggenheim, B. 1968. Streptococci of dental plaques. Caries Res. 2:147-163.

23. Mukasa, H., and H. D. Slade. 1973. Structure and immunological specificity of the Streptococcus mutans group b cell wall antigen. Infect. Immunity 7:578-585.

24. Mukasa, H., and H. D. Slade. 1973. Extraction, purification, and chemical and immunological properties of the Streptococcus mutans group "a" polysaccharide cell wall antigen. Infect. Immunity 8:190-198.

25. Van De Rijn, I., and A. S. Bleiweis. 1973. Antigens of Streptococcus mutans. I. Characterization of a serotype-specific determinant from Streptococcus mutans. Infect. Immunity 7:795-804. 